\title{
Real Interest Rate Linkages in the GCC Countries
}

\author{
Mouawiya Al-Awad \\ UAE University
}

\begin{abstract}
Linkages among real interest rates in the Gulf Cooperation Council coun tries and the US are investigated using a variety of time series tests. These tests provide an evidence of strong linkages among real interest rates within the GCC countries and between the GCC rates and the US real inter est rate in the long run, but they provide weaker evi dence for linkages in the short-run. M ore over, the US does not seem to have a dominant financial role in the GCC mar kets and that the GCC countries seem to have more integrated markets within the region than with the USA. (J E L Classifications: F 36, F 21) <Key Words : GCC, financial integration, real interest parity>
\end{abstract}

\section{Introduction}

The Gulf Cooperation Council (GCC) was established in M ay 1981 and it includes six Arab oil-states countries, namely, Saudi Arabia, the United Arab Emirates, Kuwait, B ahrain, Q atar, and Oman. Among many of its objectives is to work toward an economic integration of the GCC states and to form a

\footnotetext{
* Correspondence Address: College of Business and Economics United Arab E mirates University, PO Box 17555, AI-Ain, UAE, (Fax) 971-3-632383, (E-mail) M AWAD @uaeu. ac.ae.

(c1999 - Institute for International Economics, Sejong Institution. All rights reserved.
} 
single-market. To work toward this objective, the states forming the GCC have agreed to remove barriers to investment and trade between the member states. Therefore, they agreed to allow investment and ownership in any member country to all nationals of the GCC countries, and to remove tariffs and quotas on goods that are produced in these states and move within the GCC region. Moreover, these states have agreed to coordinate in their development and economic policies to help achieve these objectives.

In this paper the links among real interest rates are investigated in three of these states: Kuwait, Bahrain, and Q atar using the real interest parity to indicate goods and capital markets integration. ${ }^{1}$ If there is any success to the above-mentioned liberalization of capital and goods markets among the GCC states, then we should expect some strong links among real interest rates after more than 17 years since the establishment of the GCC. M oreover, these countries have relatively new financial markets and they are very similar in population size, country size, economic structure, and political and legal structures.

The rest of the paper is organized as follows: section II presents the theory of the real interest parity and some literature review, section III describes the econometric techniques used in the paper, section IV describes the data and presents the empirical evidence, and section $\mathrm{V}$ concludes.

\section{Theory and Literature Review}

The real interest parity (RIP) stems from two conditions: the uncovered interest parity (UIP) and the ex-ante purchasing power parity (EPPP):

$$
\begin{aligned}
& i_{t, j}-i_{t, j}^{*}=\Delta s_{t+j}^{e} \\
& \pi_{t, j}^{e}-\pi_{t, j}^{e}=\Delta s_{t+j}^{e}
\end{aligned}
$$

where $i_{t, j}$ and $i_{t, j}^{*}$ represent the nominal interest rates for $j$ maturity security in the domestic and foreign countries, respectively, $\Delta \mathrm{s}_{\mathrm{t}+\mathrm{j}}^{\mathrm{e}}$ represents the expected exchange rate defined as the domestic price per unit of foreign currency, and $\pi_{\mathrm{t}, \mathrm{j}}^{\mathrm{e}}$ and $\pi_{\mathrm{t}, \mathrm{j}}^{\mathrm{e}^{\mathrm{k}}}$ are the expected inflation rates in the domestic

1. The choice of these countries for the GCC members was largely dependent on the availability of data. 
and the foreign countries, respectively. The condition in (1) is the UIP and says that nominal interest rates on similar securities in two countries differ only by the expected rate of appreciation of the foreign currency. If the condition is not satisfied then investors shift to the security with higher expected yield restoring the equality. The condition in (2) is the EPPP and it states that inflation rates in two countries differ by the expected rate of appreciation of the foreign currency. If the condition is not satisfied then consumers shift to goods in the country with lower inflation rate and, so, restoring the equality. These two conditions when they are put together imply the real interest rate parity (RIP) condition, which states that the ex-ante real interest rates in the two countries are equal:

$$
r_{t, j}^{e}=r_{t, j}^{e}
$$

Or by imposing rational expectations hypothesis the RIP can be written as:

$$
r_{t, j}-r_{t, j}^{*}=e_{t, j}
$$

Where $r$ is the ex-post real interest rate and e is white noise. The RIP is taken in most of the literature to indicate financial markets integration. But, following Frankel and MacArthur [1988] and Branson [1988], real interest differential can arise because of the lack of integration of bond, currency, or goods markets. Therefore, we take linkages in real interest rates in this paper to indicate financial and goods markets integration.

A large body of literature has attempted to investigate financial markets integration (and financial and goods markets integration) by investigating relationships among real or nominal interest rates, mostly in the industrialized nations. Some of the authors (e.g., M ishkin [1984], Cumby and $M$ ishkin [1986]) use regression techniques to test the hypothesis of equality among real interest rates in different countries, which is strongly rejected. These tests may be miss-specified since they ignore the possible nonstationarity of the regressors. Another line of work, (e.g., Karfakis and M oschos [1990], Katsimbris and Miller [1993], Throop [1995], Goodwin and Grennes [1994], Chinn and Frankel [1995], Al-Awad and Goodwin [1998]), uses cointegration methodology to test for linkages among real interest rates in the long-run and uses causality methods and/or impulse responses to test for linkages among these rates in the short-run. In gener- 
al, there is no common conclusion regarding linkages among real interest rates. Karfakis and M oschos [1990] find no evidence of bivariate cointegration between nominal interest rates in Germany and other E uropean M onetary System members, but Karfakis and M iller [1993] support a long-run relationship among European real interest rates and the US but not among the German nominal interest rate and other European rates, and that the German nominal interest rates does not Granger cause other European rates. Throop [1995] finds little evidence of cointegration between the US and other industrialized countries' ex-post real interest rates and that the impulse response functions show no causal linkages among these rates in the short-run, while Goodwin and Grennes [1994] find evidence of cointegration among real interest rates in 10 industrialized countries using both bivariate and multivariate cointegration tests. M oreover, Chinn and Frankel [1995] also find an evidence of bivariate and trivariate cointegration between real interest rates in the Pacific Rim region and the US and Japan. However, they reject equality among real interest rates in those countries. Finally, AlAwad and Goodwin [1998] find a strong evidence of cointegration among exante real interest rates in the G-10 countries and they provide a weaker evidence of linkages among these rates in the short-run using out-of-sample causality tests and the impulse response functions.

\section{Econometric Techniques}

Bivariate and Multivariate cointegration tests are calculated using the standard J ohansen [1988, 1991] and Johansen and Juselius [1990] maximum likelihood technique. This procedure allows us to test for equality among real interest rates by testing for a particular cointegration vector that has zeros everywhere and $(1,-1)$ for the two interest rates that are tested to be equal. The existence of at least one cointegrating vector is taken to imply the existence of a long-run link between real interest rates in the sample. The J ohansen procedure is used also to test for unit roots in the individual series given the cointegration rank along with the usual augmented DickeyFuller [1979, 1981] (ADF) and the Phillips and Perron [1988] tests. The J ohansen test differs from the usual ADF tests in that it is a chi-square test and that the hypothesis of stationarity is stated in the null rather than in the 
alternative hypothesis.

Short-run linkages among real interest rates are investigated using a modified version of the out-of-sample Granger causality test developed by Ashley, Granger, and Schmalensee (AGS) [1980] and by the impulse response functions. The AGS test is modified to take into account cointegration relationships in the system. The modified version is superior to the usual Granger causality type tests in three directions. First, it defines causality as the ability of one variable to forecast future values of another variable rather than evaluating the goodness-of-fit as carried out by the traditional Granger causality tests, where the same data is used to estimate and evaluate the model (see Ashley [1981]). Second, it includes the US as a proxy for other important variables. As noted by Granger [1980], if a missing variable drives two variables in the system at different lags then we may find an evidence of causality even if causality does not exist in reality. Third, The procedure takes into account cointegration relationships by including an error correction form in the forecasting model. If cointegration exists, then models that do not explicitly incorporate cointegration relationships in the system will be miss-specified (Granger [1988]).

Let $r_{i}$ and $r_{j}$ be two real interest rates for countries $i$ and $j$ respectively. To test if $r_{j}$ causes $r_{i}$ (i.e., $r_{j}$ helps in forecasting future values of $r_{i}$ ) we split the data sample into two sub-periods and fit the following two models over the first sub-period:

$$
\begin{aligned}
& r_{i}=+\sum_{l}^{m} \sum_{k}^{p}{ }_{l, t-k} r_{l, t-k}+v_{t} \quad(l \neq j) \\
& r_{i}=+\sum_{l}^{m} \sum_{k}^{p} l_{l, t-k} r_{l, t-k}+\sum_{k}^{p}{ }_{j, t-k}+E C_{i j, t}+{ }_{t}
\end{aligned}
$$

Where $r_{1}$ denotes all real interest rates in the sample except $r_{j}, v_{t}$, and $\eta_{t}$ are white noise series, and $\mathrm{EC}_{\mathrm{ij}, \mathrm{t}}$ is an error correction form that relates $r_{\mathrm{i}}$ and $r_{\mathrm{j}}$. Then moving-horizon, one-step-ahead forecasts of $r_{j}$ are estimated in both models. For every observation added to the system, the models are re-estimated and the one-step-ahead forecasts are performed until the entire second sub-sample is used. Then we define $u_{\mathrm{t}}^{1}$ and $\mathrm{u}_{\mathrm{t}}^{2}$ to be the forecast errors from models (5) and (6) respectively, and the following variables are generated: 


$$
\begin{aligned}
& \Delta_{t}=u_{t}^{1}-u_{t}^{2} \\
& \Sigma_{t}=u_{t}^{1}+u_{t}^{2}
\end{aligned}
$$

Then one can estimate the following regression:

$$
\Delta_{t}={ }_{1}+{ }_{2}\left(\Sigma_{t}-\bar{\Sigma}\right)+{ }_{t}
$$

Where $\bar{\Sigma}$ is the mean of $\left(\Sigma_{\mathrm{t}}\right)$ and the error $\varepsilon_{\mathrm{t}}$ has a zero mean, and independent of $\Sigma_{\mathrm{t}} \cdot \ln (8) \delta_{1}$ represents the difference in the mean forecast errors and $\delta_{2}$ is proportional to the difference in forecast variances between models (5) and (6). Then the forecast performances of the two models are compared using both the means and the variances of the forecast errors. Therefore, we say that $r_{j}$ causes $r_{1}$ if we reject the following null hypothesis in favor of the alternative:

$$
\begin{aligned}
& H_{0}: \delta_{1}=0 \text { and } \delta_{2}=0 \\
& H_{1}: \delta_{1}>0 \text { and } / \text { or } \delta_{2}>0
\end{aligned}
$$

If we fail to reject $\mathrm{H}_{0}$, then adding $r_{j}$ to the system does not help in forecasting $r_{1}$ and, therefore, we conclude that $r_{j}$ does not cause $r_{1}$. B randt and Bessler [1983] show that since the above test does not take into account the signs of the coefficients in (8), then the F-test is a four-tailed test. M oreover, if either $\delta_{1}$ or $\delta_{2}$ is significantly negative, then the null hypothesis is not rejected. On the other hand, if either $\delta_{1}$ or $\delta_{2}$ is negative but not significantly different from zero we should perform a t-test on the other variable to test for causality.

The orthogonalized impulse response functions are also used to assist for detecting short-run linkages among real interest rates. They are calculated for every shock to each variable in a VAR system and $95 \%$ standard error bands of the impulse response functions are generated through $M$ onte Carlo integration methods.

\section{Data and Empirical Evidence}

The monthly nominal interest rates for the period 1985 to 1994 are commercial bank lending rates and are taken from the IMF's International Financial Statistics. Consumer price indices (CPI) cover the period 1984 to 
1994 and are also taken from the IM F's International Financial Statistics except for Q atar's CPI series, which is taken from the GCC D ata Book CD, and it is available only on an annual basis. CPI series for Q atar is converted from annual to monthly frequencies by fitting cubic spline curves to the CPI values to form continuous time approximations and then the monthly CPI rates are interpolated from these approximations. As noted by de Boor [1981] this method works well for non-noisy data, such as the CPI. The same method is also used to interpolate missing data for Kuwait for the period 1990:8 to 1991:2 for the nominal interest rates, and for the period 1990:7 to 1991:6 for the CPI data. Ex-post real interest rates are calculated using the Fisher's equation as the difference between inflation rates and nominal interest rates.

Table 1

\section{Multivariate and Bivariate Cointegration Tests}

\begin{tabular}{|l|c|c|c|c|c|c|c|c|}
\hline \multirow{2}{*}{\multicolumn{1}{|c|}{ Variables }} & \multicolumn{2}{|c|}{$r=0$} & \multicolumn{2}{c|}{$r=1$} & \multicolumn{2}{c|}{$r=2$} & \multicolumn{3}{c|}{$r=3$} \\
\cline { 2 - 10 } & L=max & Trace & L=max & Trace & L=max & Trace & L=max & Trace \\
\hline US, Ku, Ba, \& Qa & $43.03^{*}$ & $54.07 *$ & 11.73 & 20.04 & 5.63 & 8.31 & 2.68 & 2.68 \\
\hline Ku, Ba, \& Qa & $15.02 *$ & 25.24 & 7.92 & 10.22 & 2.30 & 2.30 & - & - \\
\hline US-Kuwait & 4.64 & 7.61 & 2.97 & 2.97 & - & - & - & - \\
\hline US-Bahrain & $11.56 *$ & 15.86 & 4.30 & 4.30 & - & - & - & - \\
\hline US-Q atar & 8.39 & 10.10 & 1.70 & 1.70 & - & - & - & - \\
\hline Kuwait-Bahrain & $12.10^{*}$ & 17.05 & 4.95 & 4.95 & - & - & - & - \\
\hline Kuwait-Q atar & 7.47 & 9.74 & 2.26 & 2.26 & - & - & - & - \\
\hline Bahrain-Qatar & $10.46 *$ & 12.62 & 2.16 & 2.16 & - & - & - & - \\
\hline
\end{tabular}

$(*)$ indicates rejection of the null hypothesis of $r=a$ vs. the alternative of $r=a+1$ at the $10 \%$ level.

Table 2

Johansen Tests for Stationarity

\begin{tabular}{|c|c|r|r|r|r|}
\hline$r=$ & $x^{2}(5)$ & USA & Kuwait & Bahrain & Q atar \\
\hline 1 & 9.49 & 32.81 & 29.89 & 32.03 & 32.35 \\
\hline 2 & 7.81 & 10.55 & 8.07 & 10.04 & 10.08 \\
\hline 3 & 5.99 & 5.25 & 2.74 & 5.06 & 4.30 \\
\hline
\end{tabular}


Table 1 presents the multivariate and the bivariate cointegration tests. Specification testing, as suggested by J ohansen [1992], indicates the inclusion of only an intercept term in the cointegration relationships when testing for cointegration in the multivariate and the bivariate settings. The first row shows the results of the multivariate cointegration test for the GCC countries with the inclusion of the USA real interest rate. B oth the L-max and the Trace tests suggest that there is one cointegrating vector among real interest rates in the GCC countries and the USA. In table 2 the J ohansen unit root tests of the individual series are presented. The $x^{2}$ test suggests that all individual interest rates are non-stationary at rank 1 as the null hypothesis of stationarity is rejected in every case ${ }^{2}$. Therefore, there is an evidence of long-run linkages among real interest rates in the GCC countries and the USA.

In the second row of table 1 the multivariate cointegration tests are repeated among the GCC countries without the inclusion of the US. U sing the L-max test, there is an evidence of one cointegrating rank among real interest rates in the GCC. The Trace test indicates that there is no cointegration among real interest rates in the GCC countries. However, as J ohansen and J uselius [1990] suggest, the trace test may lack power relative to the L-max test. Therefore, we may take this as evidence of the existence of long-run linkages among real interest rates among the GCC countries.

Bivariate cointegration tests are presented in the last six rows of table 1. Using the L-max tests, there is an evidence of cointegration in three out of six cases: the USA-B ahrain, Kuwait-Bahrain, and Q atar-Bahrain.

In table 3 the hypothesis of equality among real interest rates is tested within cointegration allowing for non-zero intercept. As noted by Chinn and Frankel [1995], by allowing for a constant in the RIP we account for the differences in default risk attributes of the debt instruments and for a time invariant risk premium. In the case of the multivariate cointegration with the inclusion of the USA, the hypothesis of equality is rejected in all cases except for two pairs of countries: the USA-Bahrain and Kuwait-Q atar. In the case of cointegration among the GCC real interest rates without the inclu-

2. The Dickey-Fuller and the Phillips and Perron tests also support non-stationarity of the interest rates and, therefore, are not reported here. 


\section{Table 3}

Tests for Equality among Real Interest Pairs within Cointegration

\begin{tabular}{|l|c|c|c|}
\hline \multirow{2}{*}{\multicolumn{1}{|c|}{ Pair }} & \multicolumn{2}{|c|}{ M ultivariate Cointegration } & \multirow{2}{*}{ Bivariate Cointegration } \\
\cline { 2 - 3 } & with USA & without USA & \\
\hline USA and Kuwait & 15.57 & - & - \\
\hline USA and Bahrain & $3.98^{*}$ & - & $0.51^{*}$ \\
\hline USA and Qatar & 14.71 & - & - \\
\hline Kuwait and Bahrain & 6.02 & $2.64^{*}$ & 5.18 \\
\hline Kuwait and Qatar & $2.58^{*}$ & $2.90^{*}$ & - \\
\hline Bahrain and Qatar & 21.95 & 6.93 & 7.83 \\
\hline
\end{tabular}

$(*)$ indicates the equality hypothesis is not rejected at the $5 \%$ level.

Table 4

AGS Out-of-Sample Granger Causality Tests

\begin{tabular}{|c|c|c|c|c|}
\hline Caused/ Causal & USA & Kuwait & Bahrain & Qatar \\
\hline \multirow{2}{*}{ USA } & $F(104.45)$ & No & $F(0.55)$ & No \\
& $(0.00)$ & Test & $(0.58)$ & Test \\
\hline \multirow{2}{*}{ Kuwait } & $F(1.52)$ & $F(44.68)$ & $T(14.79)$ & No \\
& $(0.23)$ & $(0.00)$ & $(0.00)$ & Test \\
\hline \multirow{2}{*}{ Bahrain } & $F(47.49)$ & No & $F(38.44)$ & $F(3.32)$ \\
& $(0.00)$ & Test & $(0.00)$ & $(0.048)$ \\
\hline \multirow{2}{*}{ Qatar } & $F(0.90)$ & No & No & $F(126.8)$ \\
& $(0.37)$ & Test & Test & $(0.00)$ \\
\hline
\end{tabular}

$F($.$) and T($.$) indicate F-tests and t-tests, respectively and (.) indicate the corresponding$ p-values. "No Test" indicates that one or both of the coefficients in equation (9) are significantly negative, and, therefore, the null of no causality is not rejected.

sion of the USA real rate, we fail to reject the hypothesis of equality of the real interest rates allowing for a constant in two out of three cases, namely Kuwait-Bahrain and Kuwait-Q atar real interest rates. Finally, we fail to reject the hypothesis of equality between real interest rates in only the case of USA-Bahrain when testing in the bivariate cointegration setting.

In all, cointegration tests indicate that there is an evidence of strong long- 
run linkages among real interest rates in the GCC region in one hand, and between real rates in the GCC and the USA on the other hand. M oreover, the real interest parity, taken as the equality of real interest rates allowing for a constant, is rejected in most cases, which indicates that there is no strong evidence of full integration of financial (and goods) markets among these countries.

Table 4 presents the AGS tests. An error correction component of the interest differential is included in equation (6) whenever there is an evidence of cointegration in the bivariate cointegration tests. "No Test" indicates that one or both of the parameters in equation (8) are significantly negative and, therefore, the null hypothesis of no causality is not rejected. There is an evidence of one way causality in three out of six cases: the USA real interest rate causes $B$ ahrain real rate, Bahrain real rate causes K uwait real rate, and $Q$ atar real rate causes Bahrain real rate. These results are consistent with the results of bivariate cointegration tests in table 1 since, as noted by Granger [1988], if two variables are cointegrated then there must exist a Granger causality in at least one direction so that to provide the necessary dynamics for the two variables to have an attainable long-run equilibrium. However, strong short-run linkages among real interest rates are indicated by the existence of two-way causalities. There is no evidence of twoway causalities in any case. ${ }^{3}$

In figure 1 the impulse response functions along with 95\% upper and lower standard error bands are presented. The impulse functions are calculated in a four-variable vector autoregression system and the upper and the lower er ror bands are generated, as outlined by Kloek and Van Dijk [1978], through 1000 draws for the coefficients to see how the responses change. A response to a shock is considered to be significant whenever the $95 \%$ standard error band does not include zero. Apart from the own-countries shocks, only the Kuwait real interest rate responds significantly to shocks to the Bahrain and $\mathrm{Q}$ atar real interest rates. The response to a shock to

3. In Sample Granger causality tests give results that are not consistent with the cointegration results and, moreover, they indicate that Q atar real interest rate causes the US real rate, which is not consistent with common sense expectations given the relative size of Q atar's economy to the US economy. 
Figure 1

\section{The Impulse Response Function}

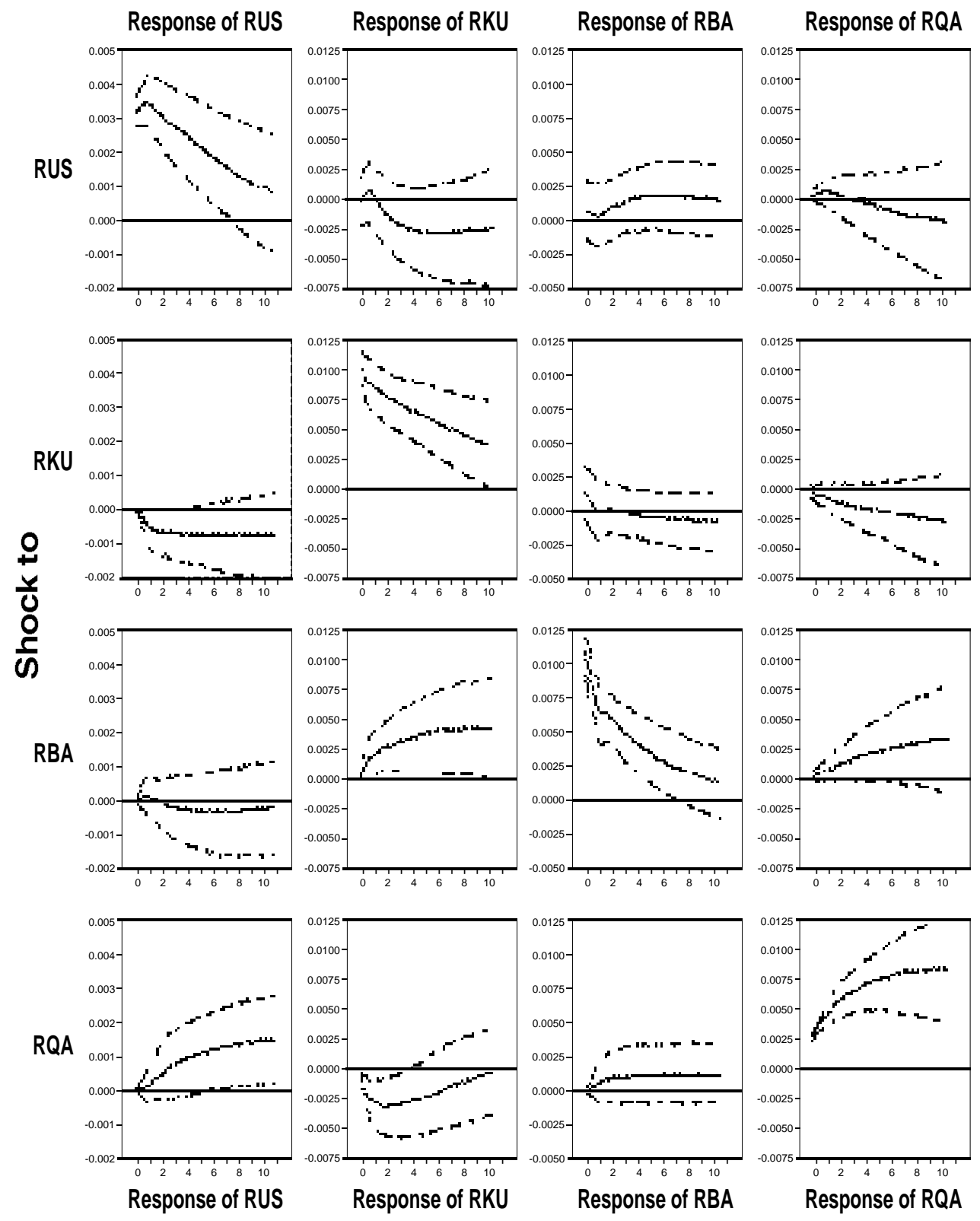

Note: Dashed lines represent upper and lower 95\%error bands. 
Bahrain real interest rate begins after around two months and dies out within eight months. The response to a shock to Q atar real interest rate is immediate but dies out within two months. M oreover, there is no evidence of any significant response to the USA real interest rate which, taken with the results of the out-of-sample Granger causality tests, implies that the US may not have a great effect on financial markets in the GCC countries. For all countries except Q atar, own-country shocks evoke significant responses that last less than ten months. Q atar real interest rate own response lasts for more than a year. In all, the short-run linkages between real interest rates among the GCC countries, on one hand, and between the GCC countries and the USA on the other hand as indicated by the impulse response functions look weaker than those indicated by the out-of-sample Granger causality test. M oreover, both the out-of-sample Granger causality tests and the impulse response functions indicate that there still exist some barriers to capital (and goods) movements within the GCC countries and between the GCC countries and the outside world, which is proxied by the USA.

\section{Conclusion}

Multivariate cointegration tests indicate the existence of long-run links among real interest rates within the GCC countries and between the GCC rates and the USA real interest rate. Moreover, there is an evidence of equality between some pairs of these rates, which, in turn, implies that there is an evidence of moving toward an integration of financial markets (and probably goods markets) among these countries. However, the out-ofsample Granger causality tests taken with the impulse response functions provide a weaker evidence of linkages among these rates in the short-run. Finally, as indicated by the out-of-sample Granger causality tests and the impulse response functions, the USA real interest rate does not seem to have a strong effect upon the GCC real interest rates, which in turn indicates that the USA may not have a dominant financial role in the GCC region. This might be explained by the fact that the GCC countries still have capital controls toward investors from outside the GCC region while they are working toward relaxing all capital controls within the GCC region. 


\section{References}

Al-Awad, M ouawiya, and Barry K. Goodwin [1998], "Dynamic Linkages among Real Interest Rates in International Capital M arkets," Journal of International M oney and Finance 17; pp. 881-907.

Ashley, Richard [1981], "Inflation and the Distribution of Price Changes Across M arkets: A Causal Analysis," E conomic Inquiry 19; pp. 650-60.

Ashley, Richard, C. W. J. Granger and R. L. Schmalensee [1980], "Advertising and Aggregate Consumption: An Analysis of Causality," Economet rica 48; pp. 1149-68.

Brandt, J on A. and David A. Bessler [1983], "Price Forecasting and Evaluation: An Application in Agriculture," J ournal of Forecasting 2; pp. 237-48 Branson, W. H. [1988], "Comments on Frankel and M acArthur's Political vs. Currency Premia in International Real Interest Differentials: A Study of Forward Rates for 24 Countries," European Economic Review 32; pp. 1083-121.

Chinn, M enzie D., and J effrey A. Frankel [1995], "Who Drives Real Interest Rates around the Pacific Rim: The US or Japan?," Journal of Interna tional M oney and Finance 14; pp. 801-21.

Cumby, Robert E., and F rederic S. M ishkin [1986], "The International Linkage of Real interest Rates: The European-US Connection," Journal of International M oney and Finance 5; pp. 5-23.

de Boor, c. [1981], "A Practical Guide to Splines," New York: Springer-Verlag.

Dickey, David A. and Wayne A. Fuller [1979], "Distribution of the Estimators for Autoregressive Time Series with Unity Roots," Journal of American Statistical Association 74; pp. 427-31.

Dickey, David A. and Wayne A. Fuller [1981], "Likelihood Ratio Statistics for Autoregressive Time Series with a Unit Root," Econometrica 49; pp. 1037-72.

Frankel, J effery A., and Alan T. M acArthur [1988], "Political vs. Currency Premia in International Real Interest Differentials: A Study of Forward Rates for 24 Countries," European E conomic Review 32; pp. 1083-121.

Goodwin, Barry K., and Thomas J. Grennes [1994], "Real Interest Rate Equalization and the Integration of International Financial Markets," Journal of International M oney and Finance 13; pp.107-24. 
Granger and C. W. J. [1980], "Testing for Causality: A Personal Viewpoint," Journal of Economic Dynamics and Control 2; pp. 329-52.

Granger and C. W. J. [ 1988], "Some Recent Developments in a Concept of Causality," Journal of E conometrics 39; pp. 199-211.

Johansen, S. [1988], "Statistical Analysis of Cointegration Vectors," Journal of E conomic Dynamics and Control 12; pp. 231-54.

Johansen, S. [1991], "Estimation and Hypotheses Testing of Cointegration Vectors in Gaussian Vector Autoregressive M odels," Econometrica 59; pp. 1151-80.

Johansen, S. [1992], "Determination of the Cointegration Rank in the Presence of a Liner Trend," Oxford Bulletin of E conomics and Statistics 54; pp.383-97.

Johansen, S. and K. Juselius [1990], "The Full Information M aximum Likelihood Procedure for Inference on Cointegration - with Application to the Demand for Money," Oxford Bulletin of Economics and Statistics 52; pp. 169-210.

Karfakis, Costas J ., and Demetrios M. M oschos [1990], "Interest Rate Linkages within the European M onetary System: A Time Series Analysis," Journal of M oney Credit and Banking 22; pp. 388-94.

Katsimbris, George M ., and Stephen M. M iller [1993], "Interest Rate Linkages within the European M onetary System: Further Analysis," Jour nal of Money, Credit, and Banking 25; pp. 771-79.

Kloek, T. and H. K. Van Dijk [1979], "Bayesian Estimates of Equation System Parameters: An Application of Integration by M onte Carlo," E conometrica 46; pp. 1-20.

M ishkin and Frederic S. [1984], "Are Real Interest Rates Equal across Countries? An Empirical Investigation of International Parity Conditions," The Journal of Finance 39; pp. 1345-57.

Throop and Adrian W. [1995], "International Financial M arket Integration and Linkages of National Interest Rates," Economic Review, Federal Reserve Bank of San Francisco V3; pp. 3-18. 